\title{
PROTECTION OF CULTURAL HERITAGE OBJECTS WITH MULTIFUNCTIONAL ADVANCED MATERIALS
}

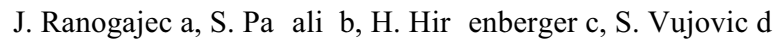 \\ a Faculty of Technology, University of Novi Sad, 21000 Novi Sad, Serbia - janjar@uns.ac.rs \\ b Ministry of Education and Science, Republic of Serbia, 11000 Belgrade, Serbia - snezana.pasalic@nauka.gov.rs \\ c Faculty of Technical Sciences, University of Novi Sad, 21000 Novi Sad, Serbia - hirhel@yahoo.co.uk \\ d Provincial Institute for Protection of Cultural Monuments, 21131 Petrovaradin, Serbia - slavaheritage@yahoo.com
}

KEY WORDS: Protection of cultural heritage, Atmospheric pollutants, Multifunctional advanced materials, HEROMAT, Dornava

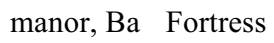

\begin{abstract}
:
The FP7 funded project HEROMAT started in November 2011 and will last for 48 months. The aim of the project is to develop innovative and environmental friendly materials that have chemical and mechanical properties tailored with respect to the protection of immovable cultural heritage assets. Through knowledge exchange among members of the international team of experts, the multidisciplinary research will offer new solutions for protection and consolidation of cultural heritage objects by the development of innovative protective materials: self-cleaning coatings, anti-microbial coatings and consolidants with or without hydrophobic properties, which will be effective for different categories of cultural heritage objects. This project aims to contribute to an efficient and long-lasting solution for the prevention of degradation, keeping the authenticity, functionality and the aesthetic appearance of the cultural assets and remaining their socio-economic benefits. The Pan-European project team coming from Serbia, Slovenia, Italy, UK and Russia, cross-links the experts and focusses their work on the restoration and consolidation of two selected historical objects, one

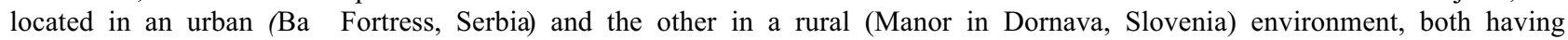
continental climate. The targeted surfaces are inorganic mineral substrates of cultural heritage objects: stone, brick, mortar, render and color finishing layers.
\end{abstract}

\section{INTRODUCTION}

The cultural heritage of immovable monuments has a powerful impact on regional society and considering the wider European region, with its complex culture diversity, represents a powerful tool for the integration process from a sociological, political and anthropological point of view. Culture and works of arts are easily understandable and consequently represent the most appealing way of establishing new links among nations. In addition, cultural heritage influences the economy by establishing business opportunities with the perspective for new work places.

Because of the recognized responsibility by relevant stakeholders and the respect for the cultural heritage monuments, significant efforts have been provided to the protection against atmospheric pollutants. The long-term conservation and restoration of the European cultural heritage is considered as a shared commitment of European societies, particularly in the context of environmental protection and sustainable living. At the same time, protection of cultural heritage is a challenging task put in front of researchers and practitioners, not only due to sociological and political reasons, but also by reason of the European economy progress and the quality of life (European Conference Declaration on Sustaining Cultural Heritage Research, 2004).

In the conservation of cultural heritage buildings, scientists deal with the degradation of unique building materials, resulting from a delicate balance of aging, unpredicted events, environmental conditions, and sometimes incorrect previous restoration treatments. Together with the climate change effects cultural heritage assets are exposed to multiple risks that can lead to irreversible damage or complete destruction. Unfortunately, there are no unique solutions for the protection of cultural heritage objects and therefore there is a great need to develop a scientific approach which will combine careful planning of ordinary and extraordinary maintenance works with the selection of proper materials ensuring overall durability and sustainable development. In order to moderate the aggressive effects of the polluted atmosphere or other decay mechanisms, protection procedures must include replacement of specific sections as well as application of new compatible materials (Price, 1996).

The project HEROMAT which started in November 2011 and lasts for 48 months aspires to develop environmental friendly materials with added value functions for restoration and conservation of immovable heritage that will be evaluated in

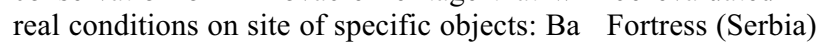
and Manor in Dornava (Slovenia). The overall goal of the project is the improvement of the physical state as well as the resistance to degradation of the materials of monuments sustaining the functionality and the aesthetic appearance through a long period of time.

\section{PROJECT CONSORTIUM}

Considering the previously existing professional contacts and long-term cooperation in scientific fields linked to project research work (Hadnadjev, 2010; Sever $\mu$ kapin, 2008; Hadnadjev, 2008) the international multidisciplinary team of experts engaged in the project jointly contributes to solving the 
concerns and problems present in the protection of immovable cultural heritage through concrete work on two selected historical sites.

Project Consortium involves universities and research institutes, public organizations for protection of cultural heritage and industrial partners:

Universities, scientific and research institutes:

- TFUNS - Faculty of Technology, Serbia, Project Coordinator

- ZAG - Slovenian National Building and Civil Engineering Institute, Slovenia

- CNR-ISTM - Institute of Molecular Science and Technologies, Italy

- UWS - University of the West of Scotland, United Kingdom

- NArFU - Northern (Arctic) Federal University, Russian Federation

- PZZSK - Provincial Institute for Protection of Cultural Monuments, Serbia

- ZVKDS/IPCHS - Institute for the Protection of Cultural Heritage of Slovenia, Slovenia

Small and medium enterprises (SMEs):

- GP HGP - Construction company HGP, Serbia

- SANING - Saning International Ltd, Slovenia

- EURA - Eura Conservation Ltd, United Kingdom

\section{PROJECT STRUCTURE}

The project is organized in ten work packages out of which seven directly involve research and technological development work, while others are management, coordination and dissemination of the project outcomes. Experienced researchers and/or experts in applied research and management are the leaders with full autonomy and responsibility for the work plan, the timelines (i.e. the milestones and deliverables) and for the scientific value of the output. The evaluation of efficiency of the new composites will be carried out first on models by means of micro-destructive laboratory analytical techniques and secondly on real cases (Manor in Dornava and Ba $\mu$ Fortress, Figures 1 and 2) through non-invasive portable equipments (Miliani, 2010; Romani, 2010).

\section{THE SELECTED CULTURAL HERITAGE ASSETS}

Dornava Manor house complex with accompanying park grounds is one of the most important monuments of the late Baroque period in Slovenia.

In the past years the manor has been studied thoroughly. The investigation was based on the research of archival sources and scientific research and gave a comprehensive image about the architectural history of the manor. The first building, which is known only after engraving of Georg Matthäus Vischer, was simple and completely rebuilt around year 1700 on behalf of Count Franz Anthony Sauer by an unknown architect. Under patronage of Count Joseph Thaddeus von Attems-Heiligenkreuz the building was reconstructed in the second half of the 18th century, according to the plans of an Austrian architect, Josef Hueber (Vienna, 1715 - Graz, 1787). Although the building of 1700 remained intact, some parts were considerably expanded and decorated in the late Baroque style.
After an ambitious 18th century renovation, the mansion underwent some construction works, which over time severely damaged the building.

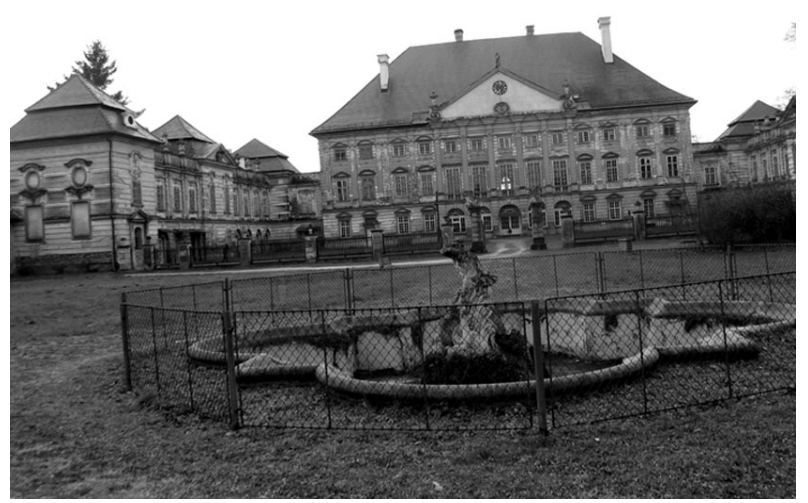

Figure 1: Manor in Dornava, Slovenia

Because of long exposure to strong degradation and inappropriate restoration actions the stone elements of the exterior - statues and ornaments of the garden, fences and main building - show only a faint picture of the past. After several decades of accelerated degradation the overall revitalization of the manor is inevitable.

Bač Fortress, Serbia (currently on UNESCO Tentative list) is the oldest medieval fortress in Vojvodina, the northern province of Serbia, built from 1338 to 1342 .

The fortress was completely surrounded by water having a pentagonal base with towers at each angle and the tallest central tower (donjon or defender tower) inside the walls of the fortress. This stronghold of the Austro-Hungarian and Ottoman empires has been in ruins for centuries due to physical, chemical and biological degradation processes. Since the salvaged parts of the Ba $\mu$ fortress illustrate coexistence, mutual understanding and cooperation of people with various religion and cultural identities living there for centuries, urgent action for degradation suppression or elimination is necessary.

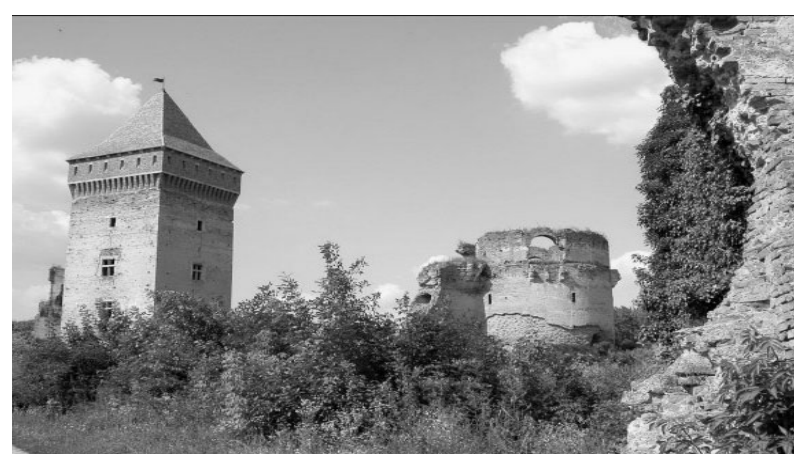

Figure 2: Ba $\mu$ Fortress, Serbia

\section{MATERIALS AND METHODS}

The project research involves the chain of activities from the synthesis, establishment of the methodology for characterization 


\section{ADVANCED MATERIALS}

and testing of novel protective materials through their pilot production and, finally, to in situ application and monitoring, giving also their life cycle assessment.

\subsection{Materials}

The output of the project is a set of novel materials applicable for the protection of different inorganic mineral substrates (stone, brick, mortar, render and color finishing layers) providing multiple added functions: consolidation, self-cleaning and anti-microbial effect.

The protective coatings would be obtained by the application of suspensions modified by the newly developed inorganicinorganic nanocomposites associated with photocatalytic materials, on different substrates and content ratio. The use of these materials based on anionic clays (layered double hydroxides, LDH) associated with photocatalytic semiconductors, such as $\mathrm{TiO} 2$, will contribute to the overall better properties of the developed coatings on the mineral substrates. These protective coatings will be developed and investigated by the international team of experts from different fields of interest tailoring their textural and morphological characteristics and enhancing their compatibility.

Different formulations of the composites will be investigated in order to define the appropriate ratios that would regulate the water permeability, the drying process improving mechanical properties and durability of protective coatings.

The evaluation procedure of these protective layers would consist of characterization of composite materials (substrate and protective layers-model samples) and in-situ monitoring (noninvasive and micro-destructive characterization) of applied materials on immovable Cultural Heritage objects.

\subsection{Methods/knowledge}

Methods/knowledge which will be developed or established for the successful execution of the project, involve:

Study of coating interactions with different mineral substrates (brick, stone, mortar, render, color finishing layers) will form the basis for the design and production of novel advanced materials; and

Study of material degradation processes for cultural heritage objects in order to find the most effective solution for protection (bio-degradation and bio-receptivity, degradation due to frost action, thermal-hydric cycling, alkali-silica reactivity, sulphate corrosion etc.):

- Study of suitable methods and techniques for monitoring and assessment of efficiency of the developed materials in laboratory and on site in real time scale

- Development of the application techniques and study of the effect of the application technique on the performance of the developed materials

- Study of durability of applied materials (short and long-term effects of protective, and consolidative materials on mineral historical substrates)

- Establishment/adjustment/development of methods for characterization of functional and other important properties of unprotected and protected targeted historical materials

- Life cycle thinking in the assessment of environmental friendly advanced protective materials (assessment of environmental impact of developed materials).

\subsection{Progress}

The project is in the middle of the first year putting the emphasis on the sampling procedure of the material from the two selected historical sites (Manor in Dornava and Ba Fortress) that will represent the basic information for further formulation and preparation of model substrates, as well as the basic information for in situ application of newly developed materials. The prepared model substrates will be subjected to simulation of degradation and subsequently characterized. It will therefore represent a suitable material base for testing the newly developed materials prior to their application onto the selected historical objects.

The sampling at the two sites was focused on the stone elements and the facade surface with the render and color finishing layers. Seven areas were selected in the case of Manor in Dornava, while forth areas were chosen from the Ba $\mu$ Fortress, according to the composition and expected degradation. The materials will be analyzed by non-invasive laboratory examination (XRF, fiber FTIR, raman, NMR-mouse) in addition to invasive characterization (petrography, SEM/EDS, $\mu$-tomography, contact angle measurements, biological characterization and $\mu$-hardness) (Hughes, 2003; Zhu, 2007). The value of the stone statues is taken into consideration; hence only non-invasive measurements will be performed.

\section{CONCLUSIONS}

The FP7 funded project HEROMAT generates know-how closely linked with main research goals set at the beginning of the project and offers collaborative experience in interdisciplinary team surroundings, with versatile subsequent dissemination activities.

The special importance was given to SMEs active involvement in all project stages, providing them with valuable insight in both new research methodologies and large-scale production lines. Partner SMEs are recognized as potential important party in the processes of production of active components on the small scale, in addition to consulting and market investigations.

The approach of the HEROMAT project ensures through consortium structure it will overcome the traditional barrier in the commercializing of the research results. At the same time, it will enhance the feedback from industry to the research institutions, essential for a lasting cooperation and widely applicable results. Moreover, the consortium encompasses both experienced and young scientists, offering the synergy of gained knowledge and fresh ideas, crucial for overall success of the project.

\section{REFERENCES}

European Conference Declaration on Sustaining Cultural Heritage Research, 2004. International Conference: Sustaining Europe's Cultural Heritage: From Research to Policy, University College London, London, UK, http://ec.europa.eu/research/environment/pdf/london_declaratio n.pdf (accessed 12 May 2012)

Hadnadjev, M. (et al.), 2010. Design of self-cleaning TiO2 coating on clay roofing tiles. Philosophical Magazine, 90, 22, pp. 2989-3002 
Hadnadjev, M. (et al.), 2008. The iron oxidation state in Mg-AlFe mixed oxides derived from layered double hydroxides: An XPS study. Applied Surface Science, 254, pp. 4297-4302

Hughes, J.J. (et al.), 2003. Mortars in Historic Buildings: a review of the scientific and conservation literature. Historic Scotland, Edinburgh, UK, ISBN 190357082 4, Book, pp. 79

Miliani, F. (et al.), 2010. In Situ Noninvasive Study of Artworks: The MOLAB Multitechnique Approach. Accounts of Chemical Research, 43, 6, pp. 728-738

Price, C.A., 1996. Stone Conservation, The Getty conservation Institute, Santa Monica, USA, Book

Romani, C. (et al.), 2010. Fluorescence Spectroscopy: A Powerful Technique for the Noninvasive Characterization of Artwork. Accounts of Chemical Research, 43, 6, pp. 837-846

Ropret, P. (et al.), 2008. Raman identification of yellow synthetic organic pigments in modern and contemporary paintings: reference spectra and case studies. Spectrochimica Acta. Part A: Molecular and Biomolecular Spectroscopy, 69, 2, pp. $486-497$

Sever $\mu$ kapin, A. (et al.), 2007. Determination of pigments in colour layers on walls of some selected historical buildings using optical and scanning electron microscopy. Material Characterization [Print ed.], 58, 11/12, pp. 1138-1147

Zhu, W. (et al.), 2007. Nanoindentation mapping of mechanical properties of cement paste and natural rocks. Materials Characterization, 58, pp. 1189-1198

\section{ACKNOWLEDGEMENTS}

The research leading to these results has received funding from the European Union Seventh Framework Programme (FP7/2007-2013) under grant agreement $n^{\circ} 282992$.

Project acronym: HEROMAT

Project title: PROTECTION OF CULTURAL HERITAGE OBJECTS WITH MULTIFUNCTIONAL ADVANCED MATERIALS

Coordinator: Faculty of Technology, University of Novi Sad, Novi Sad, Serbia

Research area: ENV-NMP.2011.3.2.1-1 Development of advanced compatible materials and techniques and their application for the protection, conservation and restoration of cultural heritage assets

Type of funding scheme: SME targeted Collaborative Project

Web address: www.heromat.tf.uns.ac.rs 